\title{
Study on the Current Condition of After-Class Reading of College Students and Enlightenment for Teaching
}

\author{
Lin $\operatorname{Lin}^{1, a^{*}}$ and Xuebo Yang ${ }^{2, b}$ \\ ${ }^{1}$ Teaching Reform and Teaching Quality Assessment Center of Bohai University, Liaoning province, \\ China \\ 2automation Research Institution of Bohai University, Liaoning province, China \\ alinlin3273@163.com, byangxuebo@gmail.com \\ ${ }^{*}$ The corresponding author
}

Keywords: College students; After-class reading; Measures

\begin{abstract}
Main function of the university is to cultivate talents, how the proposed and the needs of economic and social development to adapt to the talent training mode is the ultimate goal of each university to explore, the my university ", the author of a Book of Bohai University President by, book a comprehensive explanation of how to establish modern university system, built to adapt to social development needs of the new mode of development of the University, in today's society University School way has an important guiding significance.
\end{abstract}

\section{Introduction}

Along with the rapid development of social economy, the information technology is also improving and the regeneration of computers, mobile phones and electronic devices is more frequent which also quietly affects the reading habits of modern people, especially college students. However, the average reading amount of Chinese people is not as good as other countries. College students are the main sources reading, because reading can cultivate their mind and broaden their horizon, improve quality etc. In addition, they are more energetic and it is easier for them to embrace new things. But, it is still difficult for them to not be distracted by the colorful world and there are only few people reading, which is upset. Organization of the Text

\section{Research Overview}

Overview- Definition of Relevant Ideas. Reading process is a good mental activity, which includes memory, observation, thinking ability, focus, imagination and intelligence as well as non-intelligent factors such as determination, moral quality, courage, confidence, interest, motivation and good psychological quality etc ${ }^{[1]}$.

The Concept of After-Class Reading. Different scholars have different understandings toward reading and the one got most recognition comes from Encyclopedia of China (Education Edition): reading is a psychological process which you can get something from printed or written words. It is also a basic intelligent skill, which can be deemed as prerequisite to achieve academic success and is the sum of series process and behaviors.

After-class reading is a comparative idea to class reading, which refers to various independent reading after class and students learn from reading books and newspapers. They are independent and can read various stuff via comprehensive reading methods, including books, screens and networks etc $^{[2]}$.

The Concept of Reading Interest. Reading interest refers to the idea that people are willing to find some materials and spend time on them. Reading interests should be motivations and are psychological trend to explore reading contents as well as meanings, which can also be considered as a positive emotional attitude as well as psychological expression of happy reading. The formation of 
reading interests emerges when people are desire for the reading materials ${ }^{[3]}$.

Domestic and Foreign Research Condition. The more you read, the better you write is a successful experience of reading concluded by ancient people. To carry out after-class reading can help stimulate learning interest, and desire so that students can enrich their experience and broaden horizon, which is also beneficial to consolidate their class knowledge. By the way, it can also be considered as an important way to improve intelligence and train ability. There are a glittering array of articles regarding after-class reading of college students at home and abroad. Han Yanwei took three independent colleges of Zhejiang as examples to carry out quantitive and qualitative description on reading motivation, contents, methods and effects; She Shanghai and Liang Tao carried out research on the conditions of after-class reading time, reading types and reading contents as well as reflection of colleges students from Wuhan University, Hubei University and Central China Normal University; Huang Xiaoming etc conducted studies on four respective schools in Wuhan, which aim to explore after-class reading motivation, plan, time, main contents, carriers, sources, classic reading, online comments and evaluation etc, so as to come up with physical suggestions to guide and encourage after-class reading. In foreign countries, higher education institutions including Harvard, MIT and Utah all provide reading class with some scholars doing theoretical research and they offer doctor programs regarding after-class reading. Normal universities in France also offer reading classes. In the UK, schools including Cambridge also provides reading training and we can summarize that the liberal education in foreign countries contains a large sum of reading classes.

\section{Research Tools}

Initial Questionnaire. The author prepared questionnaire regarding after-class reading condition of college students, which contains basic information and reading condition. Basic information includes grade, gender, subjects; reading conditions includes reading motivation, trends, environment and time. The questions is made up of 22 questions.

Questionnaire Issuing. The research range covers the undergraduates of A. The author sent out questionnaires to certain undergraduates from freshman to senior-year students and selected different subjects and genders. The author sent out 400 questionnaires and all of them were returned back, among which 366 were valid and the recycling rate was $91.5 \%$.

The information of the questionnaire is recorded and analyzed by SPSS. The analysis adopts statistics theory, frequency analysis, reliability analysis, factor analysis, and methods of analysis of variance to study on the demographic information, questionnaire reliability, research dimension and exam difference.

\section{Research Results}

Demographic information of research objects

Data distribution

Table 1 Grade

\begin{tabular}{|ll|r|r|r|r|}
\hline & Frequency & Percent & $\begin{array}{c}\text { Valid } \\
\text { Percent }\end{array}$ & $\begin{array}{c}\text { Cumulative } \\
\text { Percent }\end{array}$ \\
\hline Valid & Freshman & 107 & 29.2 & 29.2 & 29.2 \\
& Sophomore & 97 & 26.5 & 26.5 & 55.7 \\
& Junior & 106 & 29.0 & 29.0 & 84.7 \\
Senior & 56 & 15.3 & 15.3 & 100.0 \\
Total & 366 & 100.0 & 100.0 & \\
\hline
\end{tabular}


Table 2 Gender

\begin{tabular}{|rl|r|r|r|r|}
\hline & Frequency & Percent & $\begin{array}{c}\text { Valid } \\
\text { Percent }\end{array}$ & $\begin{array}{c}\text { Cumulative } \\
\text { Percent }\end{array}$ \\
\hline Valid & Male & 91 & 24.9 & 24.9 & 24.9 \\
& Female & 275 & 75.1 & 75.1 & 100.0 \\
& Total & 366 & 100.0 & 100.0 & \\
\hline
\end{tabular}

Table 3 Subjects difference

\begin{tabular}{|rl|r|r|r|r|}
\hline & Frequency & Percent & \multicolumn{1}{|c|}{$\begin{array}{c}\text { Valid } \\
\text { Percent }\end{array}$} & $\begin{array}{c}\text { Cumulative } \\
\text { Percent }\end{array}$ \\
\hline Valid & Arts & 180 & 49.2 & 49.2 & 49.2 \\
& Science & 186 & 50.8 & 50.8 & 100.0 \\
& Total & 366 & 100.0 & 100.0 & \\
\hline
\end{tabular}

Judging from the above table and valid questionnaires, there are 107 freshmen, occupying 29.2\%; 97 sophomores, occupying 26.5\%; 106 junior students, occupying 29\%; 56 senior students, occupying $15.3 \%$ because it is close to graduation and there are not lots of seniors at school. In terms of gender, girls occupy $75.1 \%$ while boys occupy $24.9 \%$. In terms of art and science, $49.2 \%$ students are art students while $50.8 \%$ students are science students, they are almost equal.

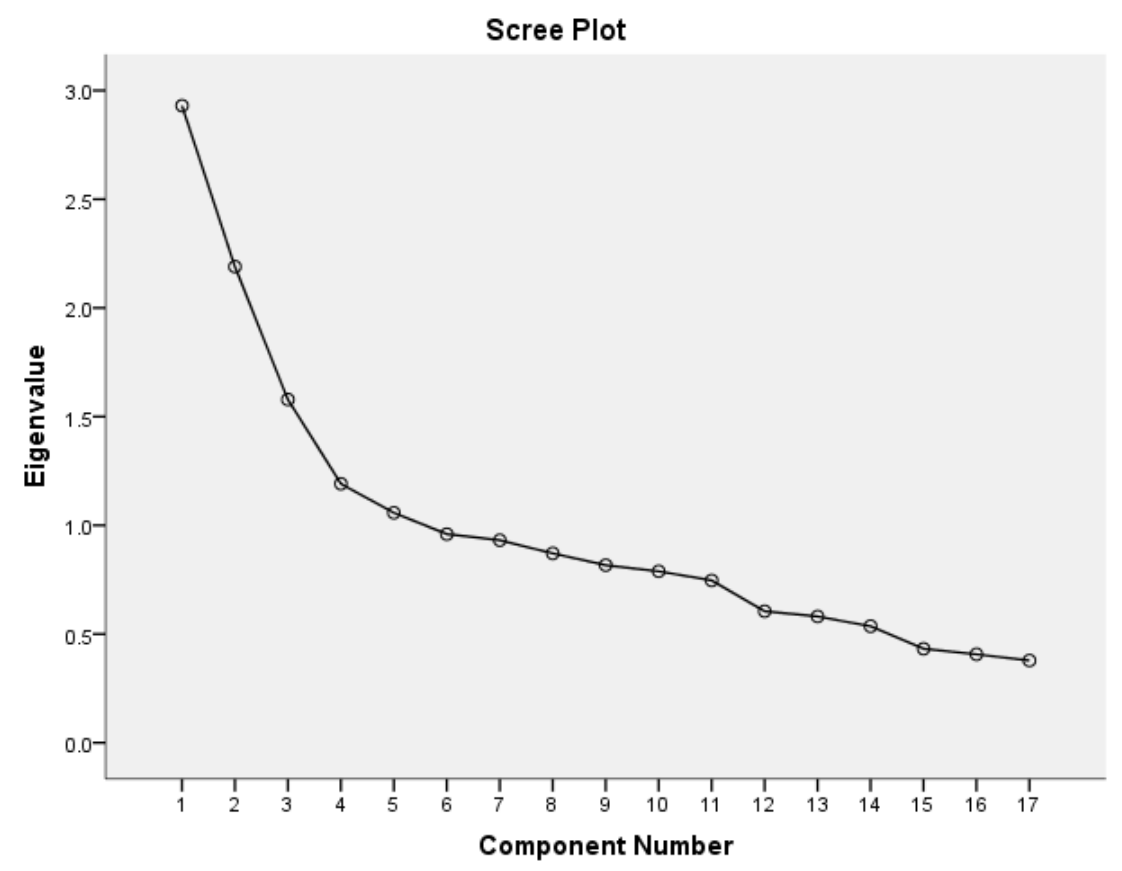

Figure 1. Scree plot and component number

According to scree plot, the eigenvalue is more than 1 and we can test from the factor 4,3 based on slope factor sharp fall. 


\section{Existing Problems and Enlightenment}

Existing Problems. Based on research, we find out the reading structure made for college students from A university is not proper because the reading time is limited to certain time; reading interests are uneven and students focus more on arts, and entertainment and professional books, which is worrying. In addition, most of them say that they are not satisfied with their current reading condition and they need further improvement.

Enlightment. Schools have to make more efforts on it and help students to adjust the reading structure. Students prefer to read art books so libraries have to improve the quality of books and introduce the latest ones of foreign countries; and students tend to read some entertainment books, which can make students relax and satisfy their novelty psychology. However, it cannot become the focus and there shouldn't be a big ratio. Moreover, schools should make the utmost to play the role of students organization, cultivate entertainment center to create good camps atmosphere. Furthermore, there should be book activities hold among different grades and classes to exchange ideas.

Fully take advantage of library rescues and guide students to carry out reasonable reading. Students prefer art books, so libraries should improve the quality and introduce both domestic and foreign books; they should also encourage students to read books when they have free time. Time is just like the water from the sponge and you have to squeeze it, which means students have to take advantage of the break time or get up earlier. A year's plan starts with Spring, and morning hour is the best time of day to work so students have to grab it and the youth time is also very valuable.

Teachers should carry out proper guidance and recommend books with high quality to guide the direction. In order to satisfy relevant indicators of teaching evaluation, teachers put too much emphasis on knowledge impartment, and ignore intelligence cultivating and training. 'When you understand the sun, atmospheric layer and earth revolve, you may ignore the glory of sunset.' Whatever knowledge students are imbued with, it is rarely for them to meet the condition so the responsibility of teachers is to make them practical. Teachers are responsible to make students be aware of the knowledge and have independent thinking ability. As teachers, they should have proper guidance to not only feed them fish but teach them how to fish so that the books will become their power.

\section{Conclusion}

Books are stepping stones for human progress, and can help us to stand on the shoulders of giants to look toward the future. Even though we find out the problems of after-class reading of students from B university based on survey, we still believe that it is better for not finding problems. Because we can come up with suggestions and seek for support, optimize the reading habits and make reasonable reading structure. Besides, we can also hold reading club to reading classic books related to the subject so as to enrich knowledge.

\section{Acknowledgements}

2014 general project of national social science "research into theories of ecological treatment of China's higher education during the period of one-way competition"(14BGL105),Economy Development project of of Liaoning province under the background of topic turn the classroom teaching evaluation mechanism research"(WY2016012), SheKeLian project in liaoning province "turn the classroom" teaching pattern in the application research on innovation of the ideological and political theory course in colleges and universities(20171slktyb-004)

\section{References}

[1] Yan Guocai. Several problems of non-intelligent factors [J]. Journal of Shanghai Normal University (Philosophy and social sciences edition) 
[2] Xu Chengyun. Elementary study on teaching- Study on after-class reading guidance. [J].2009(10)

[3] Zhang Biyin. Reading Psychology[M] Beijing, Beijing Normal University Press, 1992:25-26

[4] Han Yanwei. Research and thoughts on after-class reading of college students- Take three independent colleges of Zhejiang province as examples [J]. Social Sciences Journal of Colleges of Shanxi

[5] She Shuanghao, Liangtao. Research and thoughts on after-class reading of college students [J]. Investigation and Research

[6] Huang Xiaoming, Xing Wenming. Research and analysis on after-class reading of college students in Wuhan area, Library World, 2010 (4)

[7] Chen Jie. Strengthen after-class reading guidance, improve the quality of students- Study on the current after-class reading condition [J]. Journal of Chognqiong Petroleum College, 2001(3) 